\title{
BCG as a Vector for Novel Recombinant Vaccines against Infectious Diseases and Cancers
}

\author{
Abu Salim Mustafa \\ Department of Microbiology, Faculty of Medicine, Kuwait University, Safat 13110, Kuwait; \\ abu.mustafa@ku.edu.kw
}

Received: 5 November 2020; Accepted: 13 November 2020; Published: 4 December 2020

Bacillus Calmette-Guérin (BCG) has been widely used globally as a prophylactic vaccine to protect against tuberculosis (TB) for about a century. BCG is an attenuated strain of a pathogenic strain of Mycobacterium bovis, which was isolated from the milk of a cow suffering from TB mastitis. To attenuate M. bovis, it was sub-cultured by Albert Calmette and Camille Guérin for 13 years and passaged for 213 times on an artificial medium in vitro. The resulting organism lost its pathogeneses for animals and was termed as BCG. Interestingly, the attenuated M. bovis BCG retained its immunogenic characteristics and protected vaccinated cows against challenge with pathogenic $M$. bovis [1]. These results established the safety and efficacy of BCG vaccine in animals.

In 1921, BCG vaccination was used for the first time in an infant who was a close contact of a TB patient. On the follow-up, there were no serious side effects, and the child did not develop any signs of TB disease. Based on this success, additional newborns were vaccinated over several years and no ill effects were reported [1]. Thus, for the first time, a safe and apparently effective vaccine was available for protection against TB in humans. It is estimated that $>4$ billion people have been vaccinated with BCG in the world, and $>120$ million doses of BCG are administered annually, which makes it the most widely used vaccine in humans [2].

The protection against TB and other mycobacterial diseases in people vaccinated with BCG is due to the presence of mycobacterial antigens that activate protective immune responses against mycobacterial diseases like TB and leprosy [3-5]. However, BCG has also shown protection against diseases of non-mycobacterial origin due to its non-specific immune activator characteristics [4]. Therefore, BCG has been used as a vector for the expression and delivery of both mycobacterial and non-mycobacterial antigens. The recombinant (r)BCGs thus generated have been used as novel recombinant vaccines for protection against both infectious and non-infectious diseases.

rBCG strains expressing $M$. tuberculosis-specific antigens have been produced and evaluated in the induction of immune responses to the expressed antigens and protection against $\mathrm{TB}$ in experimental animals [6-8]. The experiments with rBCG have been further advanced to conduct phase 1 clinical trials in humans. The results showed that a rBCG strain, GamTBvac, was safe in volunteers previously vaccinated with $B C G$, and induced immune responses to $M$. tuberculosis-specific antigens [9]. Phase 2 clinical trials with GamTBvac are in progress [10].

Several rBCG strains expressing HIV antigens have been developed and assessed for the induction of specific T-cell responses in animal models [11]. A rBCG strain expressing the HIV Gag (BCG[pWB206]) induced 16-fold greater Gag-specific $\mathrm{CD}^{+} \mathrm{T}$ cells than mice immunized with recombinant modified vaccinia virus Ankara (MVA)-Gag. In addition, mice vaccinated with BCG[pWB206] were protected from a surrogate vaccinia virus challenge [12]. In mice, rBCG-pMyong2-p24 elicited enhanced p24-specific immune responses as shown by increased proliferation of HIV-1 Gag-specific CD4 ${ }^{+}$and $\mathrm{CD}^{+} \mathrm{T}$ cells, gamma interferon and antibody production, and cytotoxic $\mathrm{T}$ lymphocytes responses [13].

rBCG strains expressing HIV antigens have also been tested in prime-boost models $[12,14,15]$. Levels of Gag-specific CD4 T cells were approximately 5 fold higher in mice primed with BCG[pWB206] 
and boosted with MVA-Gag than in those receiving the MVA-Gag boost alone [12]. rBCG expressing the HIVACAT T-cell immunogen (HTI), when delivered in combination with chimpanzee adenovirus (ChAd)Ox1.HTI in mice, induced HIV-1-specific T-cell responses [15]. Furthermore, priming with rBCG doubled the magnitude of the T-cell response in comparison with ChAdOx1.HTI alone while maintaining its breadth [15].

Several recently published reports have suggested the protective effect of BCG vaccine against the development of corona virus disease (COVID)-19 and death [16-18]. However, other reports do not support this suggestion $[19,20]$. It is quite unlikely that BCG by itself can provide substantial protection against SARS-CoV-2 infection solely due to its activation of innate immunity. However, rBCG strains expressing spike protein of SARS-CoV-2 may provide a high degree of protection against COVID-19 due to the activation of both innate and virus-specific adaptive immune responses [21]. The high level of safety records of BCG in healthy humans, its potent adjuvant activity, non-requirement of a cold chain and low cost for manufacturing the vaccine makes $\mathrm{rBCG}$ an interesting candidate for protection against COVID-19 [21].

Mice immunized with a rBCG expressing gp63 antigen of Leishmania were protected against challenges with Leishmania promastigotes [22] and Leishmania major [23]. Similarly, immunization of mice with a rBCG strain expressing four antigens of Trypanosoma cruzi resulted into the induction of parasite antigen-specific T helper (Th1) and Th17 cytokine responses and provided significant protection against challenge with the parasites with a low degree of cardiac lesions 120 days after infection [24].

A host of cancers have been targeted for immunotherapy using rBCG [25]. VPM1002BC is a live $\mathrm{rBCG}$ prepared by insertion of listerolysin gene from Listeria monocytogenes into the urease $c$ gene of BCG. The intravesical application of VPM1002BC in patients with non-muscle invasive bladder cancer was found safe and well tolerated by patients and resulted in the induction of Th1-type immune response [26].

A rBCG strain expressing the detoxified S1 pertussis toxin (rBCG-S1PT) proved more effective than wildtype BCG (WT-BCG) in increasing survival time in an experimental mouse model of bladder cancer. Furthermore, human peripheral blood leukocytes stimulated with rBCG-S1PT produced increased levels of IL-6, IL-8, and IL-10; enhanced the expression of CD25 and CD69 on human CD4 ${ }^{+}$T cells; and induced higher cytotoxicity to MB49 bladder cancer cells than WT-BCG [27].

Two rBCG strains expressing Streptococcal inhibitor of complement (Sic) [rBCG-Sic], and d-alanyl carrier protein ligase (dltA) [rBCG-Sic] were tested in a growth inhibition assay using two bladder cancer cell lines (5637, T24). The growth inhibitory effects of rBCGs on bladder cancer cells were significantly enhanced as compared to WT-BCG. After $8 \mathrm{~h}$ of infection, the levels of internalization were higher in rBCG-infected bladder cancer cells than in BCG-infected cells, and cells infected with rBCGs showed increased release of antitumor cytokines, such as IL-6/12, TNF- $\alpha$, and INF- $\gamma$, resulting in inhibition of bacterial killing and immune modulation via antimicrobial peptides [28].

The immunization of mice with a rBCG strain, expressing human granulocyte macrophage colony stimulating factor (hGM-CSF) gene and the Epstein-Barr virus gene BZLF1, induced antigen-specific antibodies. The specific cytotoxic effects of the spleen cells from the rBCG group on Epstein-Barr virus-positive tumor cells were significantly higher than the cytotoxic effects of the control group cells. Morphological observations of the tumor sections from the rBCG-immunized mice showed the infiltration of $\mathrm{CD}^{+} \mathrm{T}$ and $\mathrm{CD} 8^{+} \mathrm{T}$ lymphocytes into the tumor tissues. The average tumor volume in the rBCG group was less than the average tumor volume in the control group [29].

rBCG strains expressing single mycobacterial protein antigens have shown efficacy in enhancing cytotoxicity on superficial bladder cancers in vitro and orthotopic murine bladder models [29]. Furthermore, rBCG strains expressing multiple mycobacterial antigens induced predominantly Th1-type immune responses, inhibited tumor growth, and prolonged the survival of mice with bladder tumor [29]. Several rBCG strains have been constructed that secrete cytokines with anti-tumor activity, e.g., IL-2, Il-12 IL-18 and IFN- $\alpha$. IL-2-based rBCG strains have shown that, relative to BCG 
alone, IL-2 secreting rBCG strains can improve antigen-specific proliferation, induce a more favorable IFN- $\gamma$ :IL-4 ratio, elicit higher levels of Th1 cytokines, and enhance antitumor cytotoxicity [30]. The IL-18-secreting rBCG strain induced increased secretion of IFN- $\gamma$ and GM-CSF, decreased production of IL-10, increased cellular proliferation, induced higher production of IFN- $\gamma$-secreting cells in mouse splenocytes and enhanced BCG-induced macrophage cytotoxicity against murine bladder tumor cells in a dose-dependent manner [31]. IFN- $\alpha$-secreting rBCG strains were more effective than WT-BCG in inducing IFN- $\gamma$ production from peripheral blood mononuclear cells (PBMC) and inducing PBMC cytotoxicity against bladder cancer cell lines in vitro [32].

Funding: This research was funded by Kuwait University, Research Sector grant nos. MI02/12, SRUL02/13 and GM01/15.

Conflicts of Interest: The author declares no conflict of interest.

\section{References}

1. Mustafa, A.S. BCG pros and cons and new/improved vaccines for tuberculosis. In Text Book of Biochemistry, Biotechnology, Allied and Molecular Medicine, 4th ed.; Talwar, G.P., Hasnain, S.E., Sarin, S.K., Eds.; PHI Learning Private Limited: Delhi, India, 2016; pp. 1347-1353.

2. Zhang, L.; Ru, H.W.; Chen, F.Z.; Jin, C.; Sun, R.; Fan, X.; Guo, M.; Mai, J.; Xu, W.; Lin, Q.; et al. Variable virulence and efficacy of BCG vaccine strains in mice and correlation with genome polymorphisms. Mol. Ther. 2016, 24, 398-405. [CrossRef]

3. Report on BCG vaccine use for protection against mycobacterial infections including tuberculosis, leprosy, and other nontuberculous mycobacteria (NTM) infections. Available online: https://www.who.int/ immunization/sage/meetings/2017/october/1_BCG_report_revised_version_online.pdf?ua=1 (accessed on 12 September 2020).

4. Yamazaki-Nakashimada, M.A.; Unzueta, A.; Berenise Gámez-González, L.; González-Saldaña, N.; Sorensen, R.U. BCG: A vaccine with multiple faces. Hum. Vaccin. Immunother. 2020, 16, 1841-1850. [CrossRef]

5. Mohd Hanafiah, K.; Arifin, N.; Sanders, P.R.; Othman, N.; Garcia, M.L.; Anderson, D.A. Proteomic analysis of antigen 60 complex of $M$. bovis Bacillus Calmette-Guérin reveals presence of extracellular vesicle proteins and predicted functional interactions. Vaccines 2019, 7, 80. [CrossRef]

6. Shaban, K.; Amoudy, H.A.; Mustafa, A.S. Cellular immune responses to recombinant Mycobacterium bovis BCG constructs expressing major antigens of region of difference 1 of Mycobacterium tuberculosis. Clin. Vaccine Immunol. 2013, 20, 1230-1237. [CrossRef]

7. Tkachuk, A.P.; Gushchin, V.A.; Potapov, V.D.; Demidenko, A.V.; Lunin, V.G.; Gintsburg, A.L. Multi-subunit BCG booster vaccine GamTBvac: Assessment of immunogenicity and protective efficacy in murine and guinea pig TB models. PLoS ONE 2017, 12, e0176784. [CrossRef]

8. Chen, Y.; Lin, C.; Huang, W.; Chang, J.; Su, I.; Hsu, C.; Chemg, H.; Hsu, S.; Dou, H. Recombinant bacille Calmette-Guerin coexpressing Ag85b, CFP10, and interleukin-12 elicits effective protection against Mycobacterium tuberculosis. J. Microbiol. Immunol. Infect. 2017, 50, 90-96. [CrossRef]

9. Vasina, D.V.; Kleymenov, D.A.; Manuylov, V.A.; Mazunina, E.P.; Koptev, E.Y.; Tukhovskaya, E.A.; Murashev, A.N.; Gintsburg, A.L.; Gushchin, V.A.; Tkachuk, A.P. First-in-human trials of GamTBvac, a recombinant subunit tuberculosis vaccine candidate: Safety and immunogenicity assessment. Vaccines 2019, 7, 166. [CrossRef]

10. Whitlow, E.; Mustafa, A.S.; Hanif, S.N.M. An overview of the development of new vaccines for tuberculosis. Vaccines 2020, 8, 586. [CrossRef]

11. Kilpeläinen, A.; Maya-Hoyos, M.; Saubí, N.; Soto, C.Y.; Joseph Munne, J. Advances and challenges in recombinant Mycobacterium bovis BCG-based HIV vaccine development: Lessons learned. Expert Rev. Vaccines 2018, 17, 1005-1020. [CrossRef]

12. Chapman, R.; Bourn, W.R.; Shephard, E.; Stutz, H.; Douglass, N.; Mgwebi, T.; Meyers, A.; Chin'ombe, N.; Williamson, A.L. The use of directed evolution to create a stable and immunogenic recombinant BCG expressing a modified HIV-1 Gag antigen. PLoS ONE 2014, 9, e103314. [CrossRef] 
13. Kim, B.J.; Kim, B.R.; Kook, Y.H.; Kim, B.J. Development of a live recombinant BCG expressing human immunodeficiency virus type 1 (HIV-1) Gag using a pMyong2 vector system: Potential use as a novel HIV-1 vaccine. Front. Immunol. 2018, 9, 643. [CrossRef]

14. Kilpeläinen, A.; Saubi, N.; Guitart, N.; Moyo, N.; Wee, E.G.; Ravi, K.; Hanke, T.; Joseph, J. Priming with recombinant BCG expressing novel HIV-1 conserved mosaic immunogens and boosting with recombinant ChAdOx1 is safe, stable, and elicits HIV-1-specific T-cell responses in BALB/c mice. Front. Immunol. 2019, 10, 923. [CrossRef]

15. Kilpeläinen, A.; Saubi, N.; Guitart, N.; Olvera, A.; Hanke, T.; Brander, C.; Joseph, J. Recombinant BCG expressing HTI prime and recombinant ChAdOx1 boost is safe and elicits HIV-1-specific T-cell responses in BALB/c mice. Vaccines 2019, 7, 78. [CrossRef]

16. Basak, P.; Sachdeva, N.; Dayal, D. Can BCG vaccine protect against COVID-19 via trained immunity and tolerogenesis? Bioessays 2020, e2000200. [CrossRef]

17. Joy, M.; Malavika, B.; Asirvatham, E.S.; Sudarsanam, T.D.; Jeyaseelan, L. Is BCG associated with reduced incidence of COVID-19? A meta-regression of global data from 160 countries. Clin. Epidemiol. Glob. Health 2020. [CrossRef]

18. Ogimi, C.; Qu, P.; Boeckh, M.; Bender Ignacio, R.A.; Zangeneh, S.Z. Association between live childhood vaccines and COVID-19 outcomes: A national-level analysis. medRxiv 2020. [CrossRef]

19. Ręka, G.; Korzeniowska, A.; Piecewicz-Szczęsna, H. The influence of vaccination against tuberculosis with the Bacillus-Calmette-Guérin(BCG) vaccine on COVID-19 incidence and mortality-Review of the literature. Przegl. Epidemiol. 2020, 74, 290-302. [CrossRef]

20. Hensel, J.; McAndrews, K.M.; McGrail, D.J.; Dowlatshahi, D.P.; LeBleu, V.S.; Kalluri, R. Protection against SARS-CoV-2 by BCG vaccination is not supported by epidemiological analyses. Sci. Rep. 2020, 10, 18377. [CrossRef]

21. Gupta, P.K. New disease old vaccine: Is recombinant BCG vaccine an answer for COVID-19? Cell Immunol. 2020, 356, 104187. [CrossRef]

22. Connell, N.D.; Medina-Acosta, E.; McMaster, W.R.; Bloom, B.R.; Russell, D.G. Effective immunization against cutaneous leishmaniasis with recombinant bacille Calmette-Guérin expressing the Leishmania surface proteinase gp63. Proc. Natl. Acad. Sci. USA 1993, 90, 11473-11477. [CrossRef]

23. Abdelhak, S.; Louzir, H.; Timm, J.; Blel, L.; Benlasfar, Z.; Lagranderie, M.; Gheorghiu, M.; Dellagi, K.; Gicquel, B. Recombinant BCG expressing the Leishmania surface antigen Gp63 induces protective immunity against Leishmania major infection in BALB/c mice. Microbiology 1995, 141, 1585-1592. [CrossRef]

24. Bontempi, I.; Leal, K.; Prochetto, I.; Diaz, G.; Cabrera, G.; Bortolotti, A.; Morbidoni, H.R.; Borsuk, S.; Dellagostin, O.; Marcipa, I. Recombinant Mycobacterium bovis BCG is a promising platform to develop vaccines against Trypansoma cruzi infection. Clin. Exp. Immunol. 2020, 201, 306-316. [CrossRef]

25. Zheng, Y.Q.; Naguib, Y.W.; Dong, Y.; Shi, Y.C.; Bou, S.; Cui, Z. Applications of bacillus Calmette-Guerin and recombinant bacillus Calmette-Guerin in vaccine development and tumor immunotherapy. Expert Rev. Vaccines 2015, 14, 1255-1275. [CrossRef]

26. Rentsch, C.A.; Bosshard, P.; Mayor, G.; Rieken, M.; Püschel, H.; Wirth, G.; Cathomas, R.; Parzmair, G.P.; Grode, L.; Eisele, B.; et al. Results of the phase I open label clinical trial SAKK 06/14 assessing safety of intravesical instillation of VPM1002BC, a recombinant mycobacterium Bacillus Calmette Guérin (BCG), in patients with non-muscle invasive bladder cancer and previous failure of conventional BCG therapy. Oncoimmunology 2020, 9, 1748981. [CrossRef]

27. Rodriguez, D.; Goulart, C.; Pagliarone, A.C.; Silva, E.P.; Cunegundes, P.S.; Nascimento, I.P.; Borra, R.C.; Dias, W.O.; Tagliabue, A.; Boraschi, D.; et al. In vitro evidence of human immune responsiveness shows the improved potential of a recombinant BCG strain for bladder cancer treatment. Front. Immunol. 2019, 10, 1460. [CrossRef]

28. Cho, M.J.; Kim, M.J.; Kim, K.; Choi, Y.W.; Lee, S.J.; Whang, Y.M.; Chang, I.H. The immunotherapeutic effects of recombinant Bacillus Calmette-Guérin resistant to antimicrobial peptides on bladder cancer cells. Biochem. Biophys. Res. Commun. 2019, 509, 167-174. [CrossRef]

29. Muthigi, A.; George, A.K.; Brancato, S.J.; Agarwal, P.K. Novel immunotherapeutic approaches to the treatment of urothelial carcinoma. Ther. Adv. Urol. 2016, 8, 203-214. [CrossRef] 
30. Young, S.; O’Donnell, M.; Lockhart, E.; Buddle, B.; Slobbe, L.; Luo, Y.; De Lisle, G.; Buchan, G. Manipulation of immune responses to Mycobacterium bovis by vaccination with IL-2- and IL-18-secreting recombinant bacillus Calmette Guerin. Immunol. Cell Biol. 2002, 80, 209-215. [CrossRef]

31. Luo, Y.; Yamada, H.; Chen, X.; Ryan, A.A.; Evanoff, D.P.; Triccas, J.A.; O'Donnell, M.A. Recombinant Mycobacterium bovis bacillus Calmette-Guérin (BCG) expressing mouse IL-18 augments Th1 immunity and macrophage cytotoxicity. Clin. Exp. Immunol. 2004, 137, 24-34. [CrossRef]

32. Ding, G.Q.; Yu, Y.L.; Shen, Z.J.; Zhou, X.L.; Chen, S.W.; Liao, G.D.; Zhang, Y. Antitumor effects of human interferon-alpha $2 \mathrm{~b}$ secreted by recombinant bacillus Calmette-Guérin vaccine on bladder cancer cells. J. Zhejiang Univ. Sci. B 2012, 13, 335-341. [CrossRef]

Publisher's Note: MDPI stays neutral with regard to jurisdictional claims in published maps and institutional affiliations.

(C) 2020 by the author. Licensee MDPI, Basel, Switzerland. This article is an open access article distributed under the terms and conditions of the Creative Commons Attribution (CC BY) license (http://creativecommons.org/licenses/by/4.0/). 